\title{
A Rare Case of Grade III Cherubisms
}

\section{Akhter Mahmuda*, Hossain Ryfat, Hasan Mahmudul, Mahbub-Us-Sobhan}

Bangabandhu Sheikh Mujib medical University

*Corresponding author: Akhter Mahmuda, Bangabandhu Sheikh Mujib medical University; E-mail: nazneen_2467@yahoo. com

Received Date: April 21, 2019 Accepted Date: May 24, 2019 Published Date: May 27, 2019

Citation: Akhter Mahmuda (2019) A Rare Case of Grade III Cherubism. J Dent Oral Health 6: 1-5.

\begin{abstract}
Cherubism is a benign condition affecting the maxilla and mandible, which is an autosomal dominant fibro-osseous disorder. The characteristic feature of cherubism is the "cherub" like the appearance of the patients. This occurs due to multiple cystic lesions in the maxilla and mandible that gives a rounded face appearance. Here we describe a rare case of Grade III Cherubism affecting an eight-year-old girl. The patient was diagnosed and is currently undergoing conservative treatment.
\end{abstract}

\section{Introduction}

"Cherubism" was first coined and documented in 1933 by Dr. W. A. Jones of Kingston, Ontario, describing a case of three siblings of the same family of Jewish Russian heritage. ${ }^{1}$ It is a self-limiting disease and rarely apparent before the age of two years. It occurs in children. It is a non-neoplastic disease of the bone characterized by bilateral swelling of cheeks due to bony enlargement of jaws that give the patient a typical 'cherubic' look. Beginning in early childhood, both the lower jaw (the mandible) and the upper jaw (the maxilla) become enlarged as the bone is replaced with painless, cystlike growths. These growths give the cheeks a swollen, rounded appearance and often interfere with normal tooth development. In some people, the condition is so mild that it may not be noticeable, while other cases are severe enough to cause problems with swallowing, breathing, speech, and vision. Enlargement of the jaw usually continues throughout childhood and stabilizes during puberty. The abnormal growths are gradually replaced with normal bone in early adulthood. As a result, many adults have a normal facial appearance in spite of having cherubism bony features in childhood.

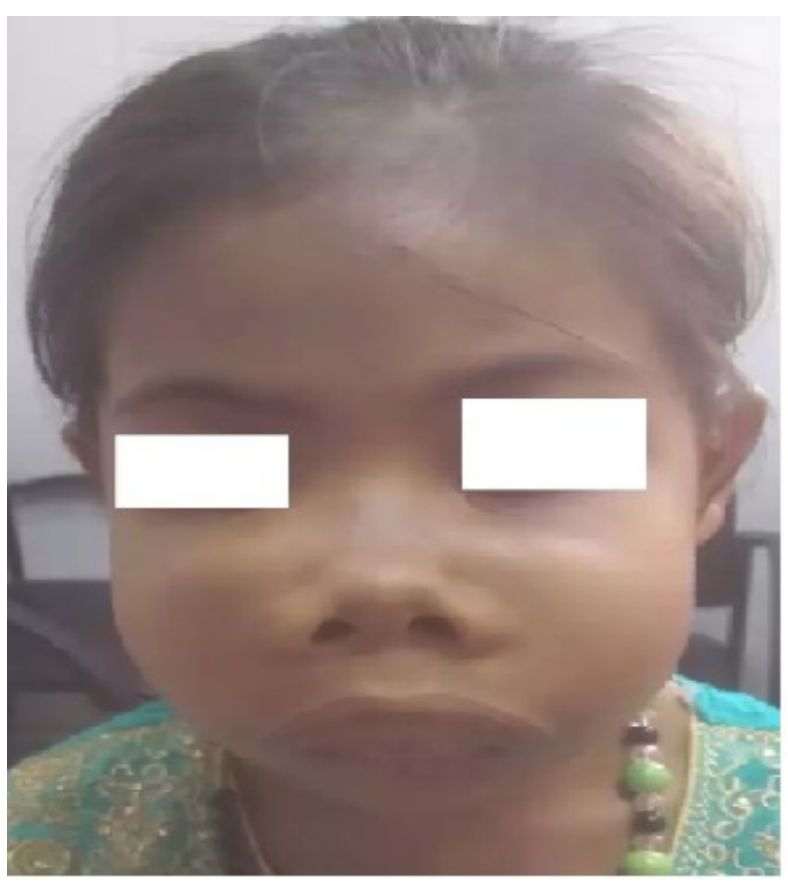

Figure 1. Frontal view of patient 


\section{Case report}

An 8-year old girl presented to us in the maxillofacial department of Bangabandhu Sheikh Mujib Medical University with the complaints of bilateral facial swelling for the last 5 years. The patient's parents stated that they first noticed the swelling when she was 3 years of age. It presented as a small swelling of the mid-face and gradually began to grow.

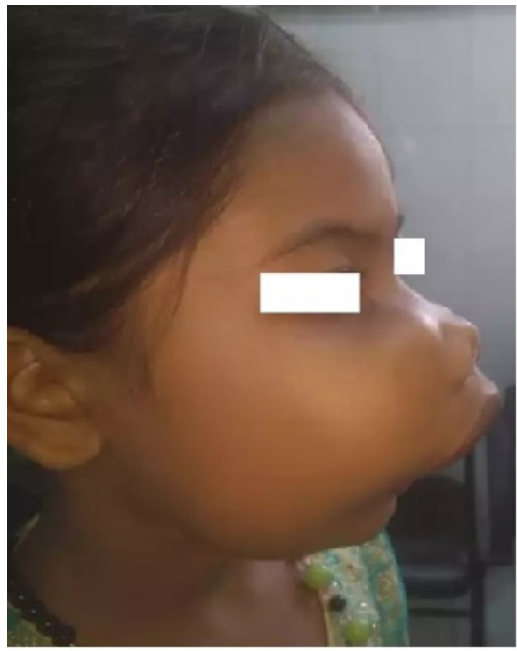

Figure 2: Lateral view of patient

Concerned, they went to a local doctor, who could not give a definitive diagnosis or treatment. Gradually over the course of 5 years, the swelling involved most of the midface particularly medially and also lateral portions of the lower third of the face. No familial history of such lesions could be determined.

On examination, large bilateral symmetrical expansion is evident affecting the mid-face extending from the malar prominence to the angle of the lip. There is the obliteration of the nasolabial fold and an appearance of flattening of the nasal bridge and flaring of the nostrils. Profile of the patient revealed bilateral swelling of the lateral aspects of the lower third of the face. The pathologies were firm to hard on palpation, non-tender, with no distinct outline. They were not tender.

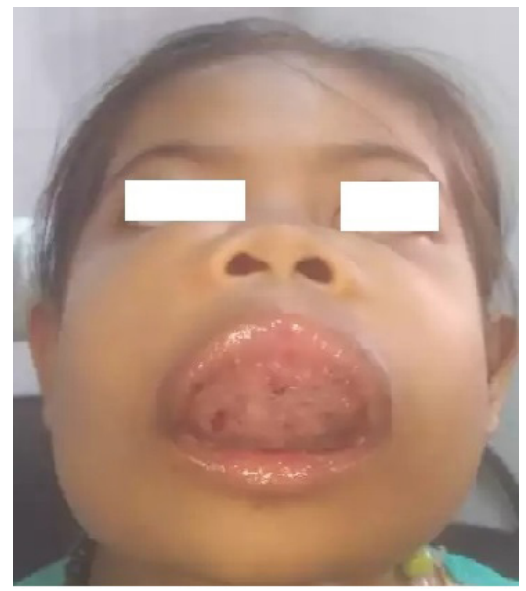

Figure 3: Intra-oral view
Intra-oral examination showed complete obliteration of the palatal arch as all of the pre-maxilla was involved with the swelling. The teeth present were displaced and deviated from its normal position, with multiple missing teeth both in maxilla and mandible. In the lower jaw, there was a gross expansion of both buccal and lingual cortex.

The patient had no difficulties in eating swallowing or speech and ocular examinations revealed no abnormality.

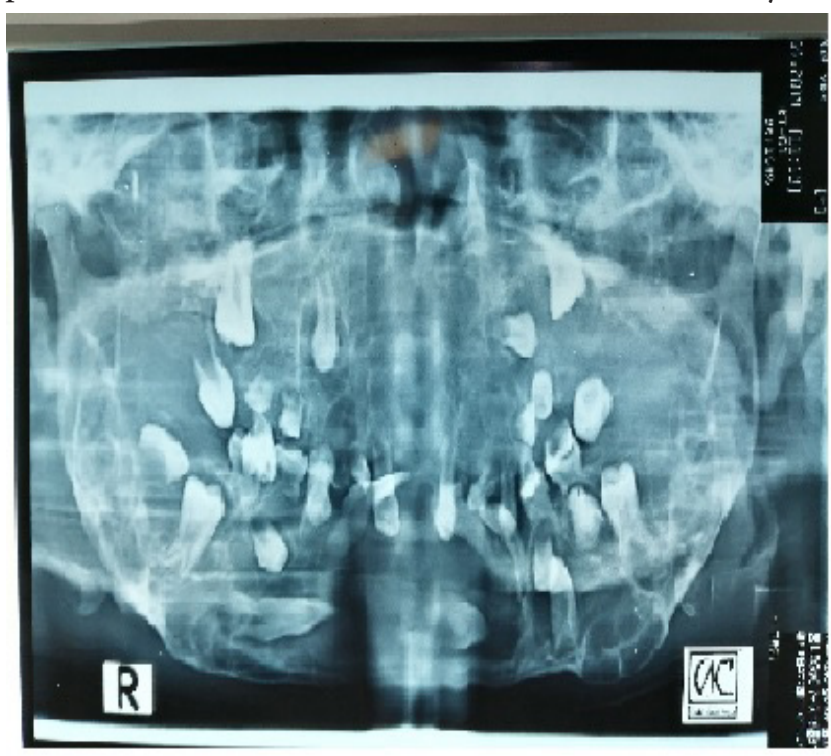

Figure 4. Orthopentamogram of patient

An orthopantomogram and a contrast CT scan of the maxillofacial region were advised to assess the extent of the involvement. Orthopantomogram reveals displacement, root resorption of multiple teeth with multilocular radiolucency both in maxilla and mandible. CT scan revealed mixed density osteolytic lesions involving the maxilla and mandible. Maxillary involvement included both premaxilla and the hard palate, both maxillary sinus and infraorbital rim. The floor of the orbit was involved as well. Upper anterior teeth appeared embedded within the lesion. The entire body and both rami of the mandible also showed gross destruction through a thin rim of alveolar bone including dentition. The posterior and lower border of the mandible and both condoyle were also intact.

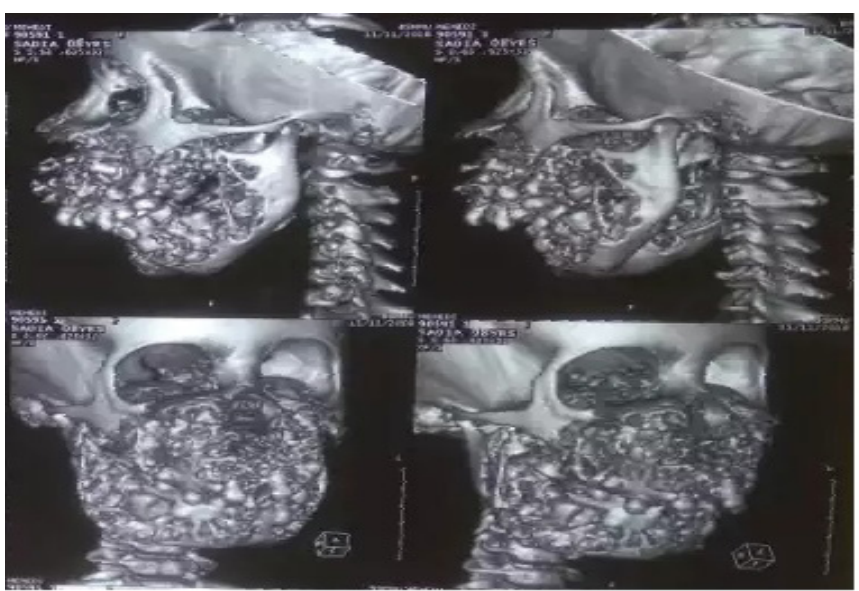

Figure 5: CT Scan of patient 
As there was no familial history of cherubism some routine investigations were advised to establish a definitive diagnosis. To rule out any metabolic abnormality we advised serum calcium, parathyroid hormone, and alkaline phosphatase assay. All were found within normal range with regards to the age of the patient. An incisional biopsy followed by histopathology was also advised. Histopathology revealed few osteoclast-like giant cells in a fibrous stroma. The fibrous stroma was highly vascular containing spindle fibroblasts arranged compactly. The histopathological diagnosis was a giant cell lesion consistent with a giant cell granuloma.

Finally, a definitive diagnosis of cherubism was established synchronizing clinical, radiographic and histopathological findings.

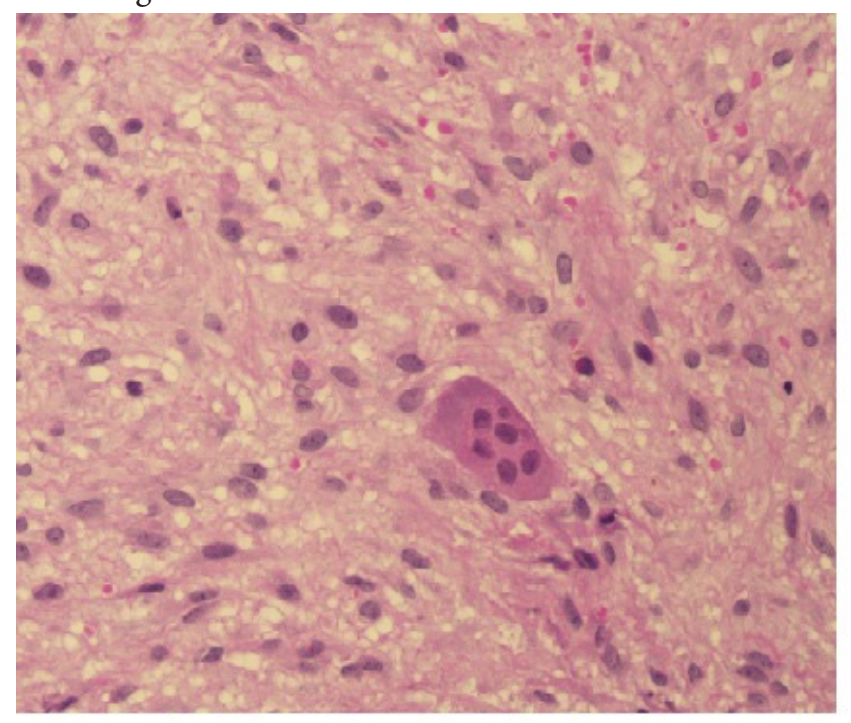

Figure 6: Histological section

\section{Discussion}

Cherubism belongs to a group of non-neoplastic bony lesion that affects only the jaws according to World Health Organization (WHO) [4]. it is also considered a member of the family of fibrous osseous diseases and some authors refer this disorder as familial fibrous dysplasia. Other names for this disease like "familial benign giant cell tumor of the jaw" and "familial multi-locular cystic disease of the jaw" have also been used.

Dr. Jones first described Cherubism in 1933, as "familial multi-locular cystic disease involving mandible and maxilla" [1]. Later on the term cherubism was used this was in particular due to the cherub-like the appearance of the patient. The cherub-like appearance was due to the symmetrical swelling of both jaws causing a rounded face appearance in addition sometimes patients were found to be looking upwards (eyes raised towards heaven) due to retraction of the lower eyelid that causes a visible iris more pronounced than the sclera [16].

Cherubism has been defined as a genetically determined alteration of tooth germ development with a mutation in gene SH3BP2 $[3,19]$. It is an inherited autosomal dominant trait which appears to have $100 \%$ penetrance in males and $50-$
$70 \%$ penetrance in females [12]. Mutations in the SH3BP2 gene lead to the production of an overly active version of this protein. The effects of SH3BP2 mutations are still under study, but researchers believe that the abnormal protein disrupts critical signaling pathways in cells associated with the maintenance of bone tissue and in some immune system cells. The overactive protein likely causes inflammation in the jaw bones and triggers the production of osteoclasts. A combination of bone loss and inflammation like conditions are responsible for the cystlike characteristic growths of cherubism [27]. Being a hereditary condition, cherubism has also been associated with some other hereditary syndromes like Ramon Syndrome, Noonan Syndrome and fragile X syndrome [12, 20, 21]. Though rare, non- familial manifestations of cherubism similar to our case have also been described [13-15]. These cases usually present with de novo mutations in the SH3BP2.

The clinical course of the condition is usually predictable with the child presenting as healthy at birth, oral symptoms begin to arise during the $2^{\text {nd }}$ or $3^{\text {rd }}$ year of life. A classic bilateral symmetrical deformity of the face due to multiple cystic lesions involving both the jaw bones is the main diagnostic criteria. The disease progresses until puberty and sometimes shows gradual regression in adulthood. Sometimes a solitary lesion or some degree of deformity may persist well into adulthood, and a few aggressive versions of cherubism have also been described. Fibrous tissues when invade the floor of the orbits, causes the floor to lift upward irregularly which may push the eyes in different directions [24]. Due to the orbital floor involvement, the inferior, lateral recti muscles and the intraconal space of the orbits may also involve $[25,26]$.

In 1957 Seward and Hawkey suggested a grading system for Cherubism

- Grade I: Involvement of bilateral mandibular molar region and ascending rami, mandible body or mentis.

- Grade II: Involvement of bilateral maxillary tuberosities as well as the lesion of grade I, diffused whole mandible.

- Grade III: Massive involvement of the entire maxilla and mandible except for the condyles.

- Grade IV: Involvement of both jaws with condyles [21].

Our case simulates Grade III Cherubism. A similar grading system was also described by Arnott in 1978 [3].

Histopathologically cherubism is similar to other fibrous dysplastic lesions and cannot be differentiated. Most of the orbital lesions consist of osteoblast cellular proliferation, surrounded by giant cells and fibroblast cells. Presence of vascular channels have been reported $[23,24]$.

The radiographic presentation usually shows multiple cystic lesions involving both jaws bilaterally. Features like "floating tooth syndrome" [16] and "ground glass appearance" 
[16] have been used to describe the radiographs. CT scan is the primary imaging technique essential for establishing a diagnosis and for the adequate course of action. It helps to identify the extent of bony involvement.

In general, the prognosis for cherubism is good. Being a self-limiting disease the "wait and see" policy has been recommended. Surgery is not a treatment of choice. But in case of expansion of tissue resulting in difficulty with airway or chewing capacity, biopsy, and surgical intervention can be done. Medical attention for aesthetic and functional concern is required.

\section{References}

1. Jones WA (1933) Familial multilocular cystic disease of the jaws. Am J Cancer 17:946-950.

2. Ueki Y, Tiziani V, Santanna C, Fukai N, Maulik C, et al. (2001) Mutation in the gene encoding c-abi binding protein SH3BP2 cause cherubism. Nat Genet 28:125-126.

3. Arnott DG (1978) Cherubism- An initial unilateral presentation. Br J Oral Surg 16:38-46.

4. Pindborg JJ, Kramer IR (1971) World Health Organization. 1st ed. Geneva: Histological typing of odontogenic tumors, jaw cysts, and allied lesions18-19.

5. Thompson N (1959) Cherubism: Familial fibrous dysplasia of the jaw. Br J Plast Surg 12:89-103.

6. MC Caledon JL, Anderson DE, Cornelius EA (1962) Cherubism: hereditary fibrous dysplasia of the jaws. II. Pathologic considerations. Oral Surg Oral Med Oral Pathol 15:1741 .

7. Wayman JB (1978) Cherubism: a report on three cases. Br J Oral Surg 16:47-56.

8. Thompson ER (1962) Multiple giant-cell tumors: report of a case. Oral Surg Oral Med Oral Pathol15:69-73.

9. Bruce KW, Brewer A, Kennedy RL (1963) Familial intraosseous fibrous swellings of the jaws (cherubism) Oral Surg Oral Med Oral Pathol 6:995-1014.

10. Bloom J, Checker FM, Thoma KH (1962) Multiple giant-cell lesions of bone: report of a case. Oral Surg Oral Med Oral Pathol 15:74-83.

11. Quan F, Grompe M, Jakobs P, Popovich BW (1995) Spontaneous deletion in the FMR 1 gene in a patient with fragile X syndrome and cherubism. Hum Mol Genet 4:1681-1684.

12. Rattan V, Utreja A, Singh BD, Singh SP (1997) Non familial cherubism- A case report. J Indian Soc Pedod Prev Dent 15:118-120.

13. Brad WN, Douglas DD, Carl MA, Jerry EB (2005) Neville's Text Book of Oral Pathology. 2nd ed. New Delhi, El- sevier: Bone pathology 547-549.

14. Von Wowern N (2000) Cherubism-a 36-year longterm follow-up of two generations in different families and review of the literature. Oral Surg Oral Med Oral Pathol Oral Radiol Endod 90:765-772.

15. Meng XM, Yu SF, Yu GY (2005) Clinicopathological study of 24 cases of cherubism. Int J Oral Max Surg 34:350356.

16. Shah N, Handa KK, Sharma MC (2004) A malignant mesenchymal tumor arising from cherubism: a case report. J Oral Maxillofac Surg 62:744-749.

17. Hyckel P, Berndt A, Schleier P, Clement JH (2005) Cherubism-new hypothesis on pathogenesis and therapeutic consequences. J Cranio-Maxillofac Surg 33:61-68.

18. Ramon Y, Berman W, Bubiss JJ (1967) Gingival fibromatosis combined with cherubism. Oral Surg Oral Med Oral Pathol 24:435-448.

19. Dunlap C, Neville B, Vickers RA, et al. (1989) The Noonan syndrome/cherubism association. Oral Surg Oral Med Oral Pathol 67:698-705.

20. De Tomasi DC, Hann JR, Stewart HM (1985) Jr Cherubism: report of a non-familial case. J Am Dent Assoc 111:455-457.

21. Seward GR, Hankey GT (1957) Cherubism. Oral Surg Oral Med Oral Pathol10:952-974.

22. Font R.L, et al. (2003) Giant cell reparative granuloma of the orbit associated with cherubism. Ophthalmology 110:1846-1849.

23. Hawes M.J (1989) Cherubism, and its orbital manifestations. Ophthal Plast Reconstr Surg 5:133-140.

24. Ahmadi A.J, G.E. Pirinjian, and B.S. Sires (2003) Optic neuropathy and macular chorioretinal folds caused by orbital cherubism. Arch Ophthalmol 121: 570-573.

25. Carroll A.L. and T.J. Sullivan (2001) Orbital involvement in cherubism. Clin Exp Ophthalmol 29: 38-40.

26. Mir Mohammad Sadeghi A, et al. (2015) Cherubism: report of three cases and literature review. Orbit 34:33-37.

27. Reichenberger EJ, Levine MA, Olsen BR, et al. (2012) The role of SH3BP2 in the pathophysiology of cherubism. Orphanet J Rare Dis.7: S5. 
Submit your manuscript to a JScholar journal and benefit from:

- Convenient online submission

ฯ Rigorous peer review

q Immediate publication on acceptance

- Open access: articles freely available online

I High visibility within the field

- Better discount for your subsequent articles

Submit your manuscript at http://www.jscholaronline.org/submit-manuscript.php 